\title{
Is there a hypercoagulable state after off-pump coronary artery bypass surgery? What do we know and what can we do?
}

Paul A. Kurlansky, MD
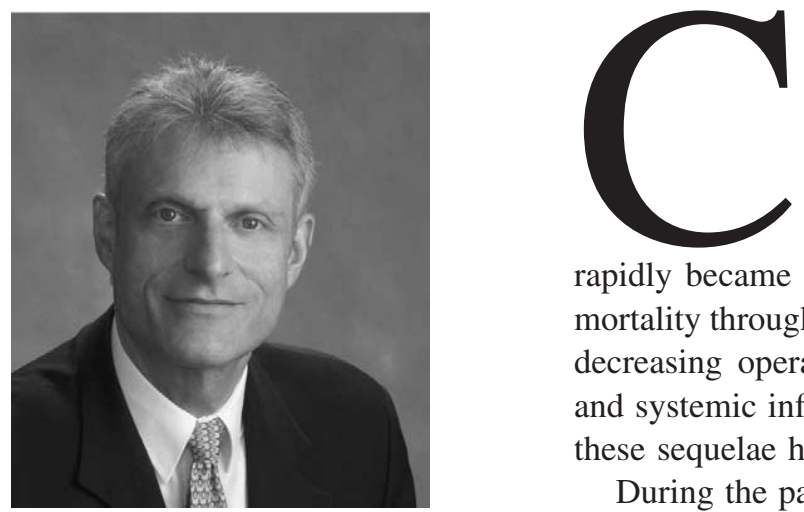

oronary artery bypass graft $(\mathrm{CABG})$ surgery on a beating heart was introduced with suture techniques and local stabilization by Kolessov in $1967 .{ }^{1}$ However, cardiopulmonary bypass and cardioplegic arrest, with their ability to provide a quiet bloodless field for the construction of precise and delicate surgical anastomoses, offered compelling advantages compared with the off-pump approach and rapidly became more widely accepted. ${ }^{2}$ With the dramatic reduction of operative mortality throughout the ensuing decades, surgeons began to focus their attention on decreasing operative morbidity, especially conditions associated with neurologic and systemic inflammatory influences after CABG surgery. Traditionally, many of these sequelae have been ascribed to the use of cardiopulmonary bypass.

During the past decade, there has been a dramatic resurgence in the application of off-pump technology in CABG surgery. This has inspired remarkable advances in the techniques of localized tissue stabilization and a greater understanding of the physiology of beating heart mobilization and exposure. An avalanche of reports in the literature has demonstrated the early safety and efficacy of the procedure. ${ }^{3}$ More than $20 \%$ of CABG procedures performed nationwide apply off-pump technology. However, considerable controversy remains regarding the relative merits and longterm outcomes of this approach to coronary revascularization. ${ }^{4}$

One area of concern, and even greater uncertainty, surrounds the issue of the existence of a hypercoagulable state after off-pump CABG surgery. Are patients undergoing off-pump CABG surgery relatively more hypercoagulable postoperatively than their counterparts undergoing on-pump CABG surgery? Such a hypothesis is indeed reasonable in view of the acute phase activation of clotting factors that follow off-pump CABG surgery (as well as surgery in general) and the lack of platelet, fibrinolytic, and other abnormalities related to the heart-lung machine. However, there was no evidence to indicate a clinical problem associated with the procedure until Mariani and colleagues ${ }^{5}$ awakened our concern with their report in 1999. They reviewed 22 consecutive off-pump cases and found a postoperative increase in procoagulant activity, represented by prothrombin factor 1 and 2, which was also accompanied by an increase in von Willebrand factor (endothelial activation) and fibrinolysis. Although Mariani and colleagues ${ }^{5}$ demonstrated no clinical sequelae during their brief follow-up of this limited series of patients with internal thoracic artery (ITA) grafts, they recommended the institution of an aggressive perioperative anticoagulant regimen in all off-pump CABG cases.

What is the major concern? Clearly, a pattern of deep venous thrombosis, pulmonary embolism, or arterial thrombosis would be a source of serious concern to the cardiac surgeon. However, the already extensive clinical experience fails to demonstrate such a pattern. Perhaps a less apparent concern would be the occurrence of acute graft closure. Careful evaluation of the current body of knowledge would indicate just the opposite, with acute graft patency rates exceeding $90 \%$ in virtually all cases reviewed. The information in Table 1 summarizes the results of a series of angiographic patency studies after off-pump CABG surgery. ${ }^{6-15}$ Even accounting for extensive variability in patient selection, operative technique, and heparin and

The Journal of Thoracic and Cardiovascular Surgery • Volume 126, Number 17 
TABLE 1. Angiographic patency after off-pump coronary bypass surgery

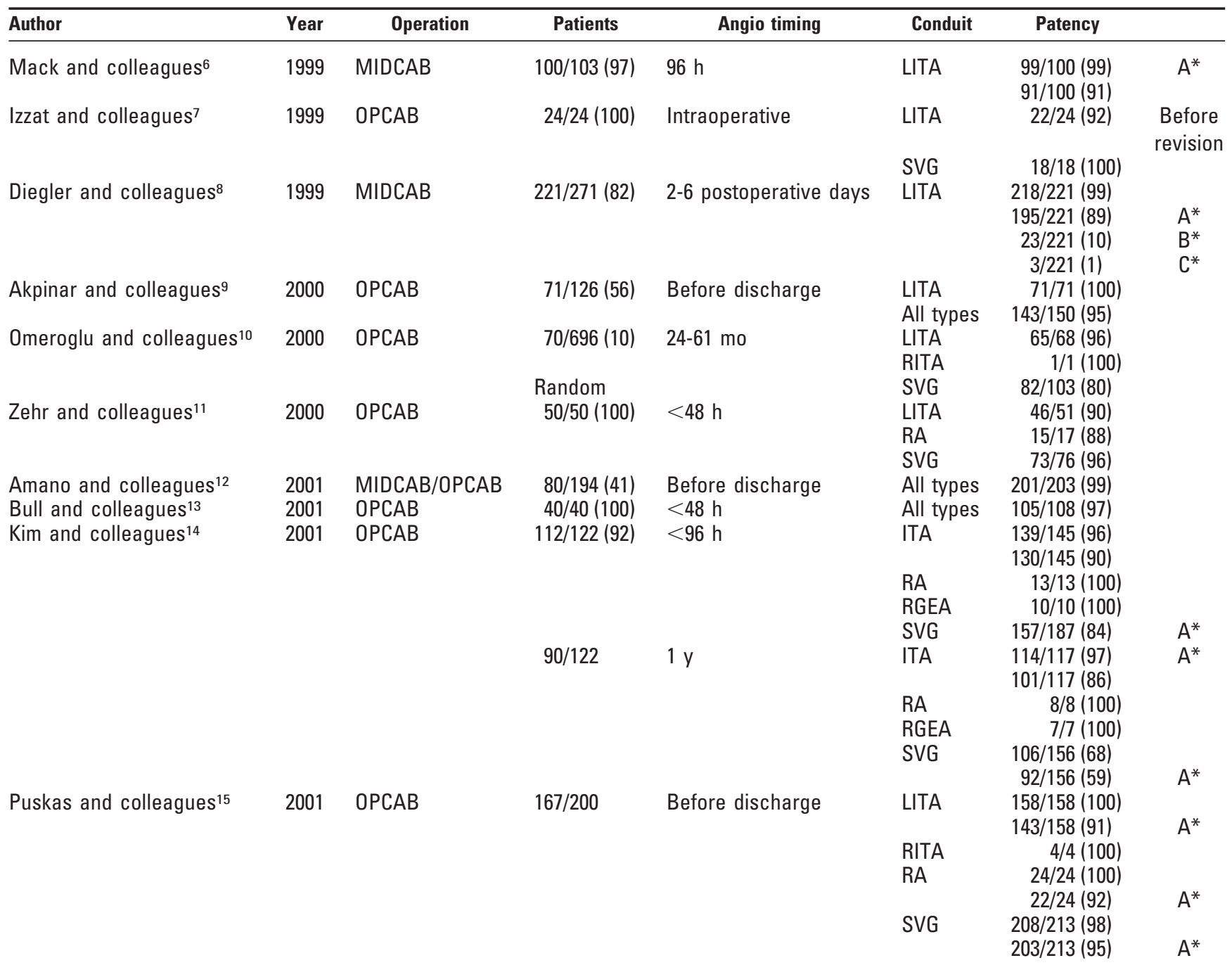

Numbers in parentheses are percentages. MIDCAB, Minimally invasive direct coronary artery bypass; OPCAB, off-pump coronary artery bypass; $L I T A$, left internal thoracic artery; RITA, right internal thoracic artery; $R A$, radial artery; $R G E A$, right gastroepiploic artery; $S V G$, saphenous vein graft; $A^{*} B^{*}{ }^{*}{ }^{*}{ }^{*}$ Fitzgibbon classification.

antiplatelet regimens in these studies, it does not seem that acute graft closure secondary to a hypercoagulable state is a valid clinical concern.

Careful analysis of the data exposes a more menacing problem. Kim and associates ${ }^{14}$ conducted a 3 -group study that compared a cohort of patients undergoing off-pump CABG surgery, a group of patients undergoing on-pump CABG surgery, and a similar group of patients undergoing on-pump CABG surgery whose grafts were constructed on the beating heart during the pre-off-pump CABG learning phase. At 1-year follow-up, ITA patency was similar among the groups. Saphenous vein graft (SVG) patency was $88 \%$ in patients undergoing CABG surgery, $87 \%$ in patients undergoing on-pump beating heart surgery, and $68 \%$ in patients undergoing off-pump surgery $(P<.01) .{ }^{14}$ There are many questions that can be raised about a retrospective study of nonconcurrent groups of patients who underwent operations at different points during the learning curve and with variable follow-up. The major underlying issue is more subtle and one that must be addressed.

It has been learned from multiple pathologic and clinical studies that vein graft disease takes many forms: thrombosis (acute), intimal hyperplasia (subacute), and graft atherosclerosis (chronic). ${ }^{16}$ Although intimal hyperplasia may take months to occur, and atherosclerosis 1 year or more to develop, the initiating events (intimal injury, platelet activation, thrombus formation, macrophage infiltration, and smooth muscle cell activation) all occur in the acute postoperative period of SVG (but not during ITA) healing. Therefore, during the early postoperative period, even in the 
absence of any clinically manifest adverse events, the groundwork may be laid for the occurrence of multiple late events, thus adversely impairing long-term graft patency. In short, have we, in our enthusiasm to reduce perioperative morbidity, created a sleeping giant of late graft closure?

Casati and colleagues ${ }^{17}$ compared multiple hematologic variables in patients undergoing off-pump versus on-pump CABG surgery. They documented that a decrease in platelet count and activation of fibrinolysis were more profound in on-pump surgery, whereas the activation of fibrinogen and other acute phase reactants (consistent with the deposition of thrombus at surgical sites of injury) seemed to be more evident during the first postoperative day in patients undergoing off-pump CABG surgery. Therefore, patients undergoing off-pump coronary artery bypass surgery might well be expected to be more prone to graft closure. As disconcerting as these findings may seem, a comparative analysis of perioperative hemostatic function in patients who did and did not experience SVG occlusion within 3 months of surgery found an increase in plasma plasminogen activator inhibitor-1 activity to be the only postoperative hemostatic measurement predictive of subsequent SVG closure. ${ }^{18}$ Notably, the classic atherosclerotic risk factors were found to be more powerful predictors than the hemostatic factors, a finding corroborated by the Cleveland Clinic experience. ${ }^{19}$

The emergence of long-term comparative studies demonstrating the clinical equivalence of on-pump and offpump CABG surgery has been most encouraging. ${ }^{20}$ However, in the absence of convincing data, there is currently extreme variability in the management of anticoagulation and antiplatelet agents in off-pump CABG surgery. ${ }^{21}$

In the presence of a well-founded concern for the impact of a relatively hypercoagulable state after off-pump CABG surgery on long-term graft patency, and in the absence of valid data indicating appropriate guidelines, what reasonable recommendations can be offered at this time? First, arterial conduits, especially in situ ITA grafts, have been demonstrated to be less prone to the pathogenesis of late graft closure than SVG grafts and are considered to be the conduit of choice in myocardial revascularization. As a result, off-pump CABG surgery may prove to be an even stronger indication for the use of arterial grafting than conventional on-pump surgery.

Second, risk factor modification is known to affect the course of both graft and native coronary disease in all patients undergoing CABG surgery, and patients undergoing off-pump CABG surgery are no exception. Therefore, careful attention to risk factor modification may prove critical in maintaining graft patency and improving long-term clinical results.

Third, in view of the lower incidence of bleeding complications after off-pump CABG surgery, consideration should be given to limiting the reversal of heparin intraoperatively. ${ }^{22}$

Fourth, in view of the well-documented and common unresponsiveness to aspirin, ${ }^{23}$ as well as the considerable effectiveness of thienopyridines (ticlopidine and its safer successor clopidogrel) reported in both the cardiology ${ }^{24}$ and cardiac surgical literature, ${ }^{25}$ serious consideration should be given to the perioperative (and perhaps the prolonged postoperative) use of clopidogrel.

Fifth, the recent success of drug-eluting stents ${ }^{26}$ raises serious concerns regarding the use of SVGs in stentable vessels. These data, although still early, pose a theoretical issue in the use of combined procedures for patients unable to receive all-arterial conduits.

Sixth, gene therapy may have a dramatic impact on arresting the progression of SVG disease, ${ }^{27}$ and advances in this area may have particular relevance to patients undergoing off-pump coronary artery bypass surgery.

Perhaps the most helpful recommendation would be to direct research efforts toward managing the perioperative hypercoagulable state and its long-term impact on graft patency in patients undergoing off-pump coronary revascularization.

\section{References}

1. Kolessov VI. Mammary artery-coronary artery anastomosis as a method of treatment for angina pectoris. J Thorac Cardiovasc Surg. 1967;54:535-44

2. Favaloro RG, Effler DB, Groves LK, Shelton WC, Sones FM Jr. Direct myocardial revascularization by saphenous vein graft. Present operative techniques and indications. Ann Thorac Surg. 1970;10:97-111.

3. Hart JC, Puskas JD, Sabik JF 3rd. Off-pump coronary revascularization: current state of the art. Semin Thorac Cardiovasc Surg. 2002;14: 70-81.

4. Gardner TJ. Off-pump CABG safer for the brain. Presented at $81 \mathrm{st}$ Annual Meeting of The American Association for Thoracic Surgery, May 9, 2001, San Diego, California.

5. Mariani AM, Gu J, Boonstra PW, et al. Procoagulant activity after off-pump coronary operation: is the current anticoagulation adequate? Ann Thorac Surg. 1999;67:1370-5.

6. Mack JM, Magovern JA, Acuff TA, et al. Results of graft patency by immediate angiography in minimally invasive coronary artery surgery. Ann Thorac Surg. 1999;68:383-90.

7. Izzat MB, Khaw KS, Atassi W, Yim AP, Wan S, El-Zufari MH. Routine intraoperative angiography improves the early patency of coronary grafts performed on the beating heart. Chest. 1999;115:98790 .

8. Diegeler A, Matin M, Kayser S, et al. Angiographic results after minimally invasive bypass grafting using the minimally invasive direct coronary bypass grafting (MIDCAB) approach. Eur J Cardiothorac Surg. 1999;15:680-4.

9. Akpinar B, Guden M, Sagbas E, Sanisoglu I, Aytekin V, Bayindir O. Off-pump coronary artery bypass grafting with use of the octopus 2 stabilization system. Heart Surg Forum. 2000;3:282-6.

10. Omeroglu SN, Kirali K, Guler M, et al. Midterm angiographic assessment of coronary artery bypass grafting without cardiopulmonary bypass. Ann Thorac Surg. 2000;70:844-50.

11. Zehr KJ, Handa N, Bonilla LF, Abel MD, Holmes DR Jr. Pitfalls and results of immediate angiography after off-pump coronary artery bypass grafting. Heart Surg Forum. 2000;3:293-9.

12. Amano A, Hirose H, Takahashi A, Nagano N. Off-pump coronary 
artery bypass. Mid-term results. Jpn J Thorac Cardiovasc Surg. 2001; 49:67-78.

13. Bull DA, Neumayer LA, Stringham JC, et al. Coronary artery bypass grafting with cardiopulmonary bypass versus off-pump cardiopulmonary bypass grafting: does eliminating the pump reduce morbidity and cost? Ann Thorac Surg. 2001;71:170-5.

14. Kim KB, Lim C, Lee C, et al. Off-pump coronary artery bypass may decrease the patency of saphenous vein grafts. Ann Thorac Surg. 2001;72:S1033-7.

15. Puskas JD, Thourani VH, Marshall JJ, et al. Clinical outcomes, angiographic patency, and resource utilization in 200 consecutive offpump coronary bypass patients. Ann Thorac Surg. 2001;71:1477-84.

16. Motwani JG, Topol EJ. Aortocoronary saphenous vein graft disease: pathogenesis, predisposition and prevention. Circulation. 1998;97: 916-31.

17. Casati V, Gerli C, Franco A, et al. Activation of coagulation and fibrinolysis during coronary surgery: on-pump versus off-pump techniques. Anesthesiology. 2001;95:1103-9.

18. Moor E, Blombac M, Silveira A, et al. Haemostatic function in patients undergoing coronary artery bypass grafting: perioperative perturbations and relations to saphenous vein graft closure. Thromb Res. 2000;98:39-49.

19. Lytle BW, Loop FD, Cosgrove DM, et al. Long-term (5 to 12 years) serial studies of internal mammary artery and saphenous vein coronary bypass grafts. J Thorac Cardiovasc Surg. 1985;89:248-58.

20. Angelini GD, Taylor FC, Reeves BC, Ascione R. Early and midterm outcome after off-pump and on-pump surgery in beating heart against cardioplegic arrest studies (BHACAS 1 and 2): a pooled analysis of two randomized controlled trials. Lancet. 2002;359:1194-9.

21. D'Ancona G, Donias HW, Karamanoukian RL, et al. OPCAB therapy survey: off-pump clopidogrel, aspirin or both therapy survey. Heart Surg Forum. 2001;4:354-8.

22. Nader ND, Khadra WZ, Reich NT, Bacon DR, Salerno TA, Panos AL. Blood product use in cardiac revascularization: comparison of on-and off-pump techniques. Ann Thorac Surg. 1999;68:1640-3.

23. Steinhubl SR. Antiplatelet agents in cardiology: the choice of therapy. Ann Thorac Surg. 2000;70:S3-8.

24. Schomig A, Neumann F-J, Kastrati A, et al. A randomized comparison of antiplatelet and anticoagulant therapy after the placement of coronary-artery stents. N Engl J Med. 1996;334:1084-9.

25. Bhatt DL, Chew DP, Hirsch AT, Ringleb PA, Hacke W, Topol EJ. Superiority of clopidogrel versus aspirin in patients with prior cardiac surgery. Circulation. 2001;103:363-8.

26. Teirstein PS. Living the dream of no restenosis. Circulation. 2001; 104:1996-8.

27. Mangi AA, Dzau VJ. Gene therapy for human bypass grafts. Ann Med. 2001;33:153-5.

\section{JTCVS On-Line Manuscript Submission and Review}

\section{Please visit http://www.editorialmanager.com/jtcvs/}

Effective September 15, 2001, authors and reviewers may submit manuscripts and reviews electronically via Editorial Manager, our new Web-based system with full electronic submission, review, and status update capabilities.

As we move from paper to electronic submissions, the Editorial Office will make proxy submissions of all manuscripts accompanied by a diskette containing the electronic files of the text, tables, and figures. Editors, authors, and reviewers will receive automatic e-mails when significant events occur.

We strongly encourage all authors and reviewers to use Editorial Manager. Although we will continue to accommodate the submission of paper manuscripts for some months, our goal is to be completely electronic within 9 to 12 months.

All individuals currently in our database for whom we have e-mail addresses will receive via e-mail a system-assigned username and password that can be used to log in to the system without prior registration. All those not receiving the e-mail must register the first time they use the system.

As with any broad systemic change, the conversion to the new system will take some time to complete. We ask your patience as we replace our in-office database with the new system. We also encourage you to take advantage of the speed and efficiency that the new system will provide for us all: editor, author, reviewer, and publisher. 